\title{
Ações desenvolvidas no PIBID mediante um olhar biogeográfico do Jardim Botânico Rodriguez Alves em Belém-Pa.
}

\author{
Actions developed in PIBID by a biogeographical look Botanical Garden Rodriguez Alves \\ in Belém-Pa.
}

Paixão소 A. S. O.; Borges², A. C. anandapaixao93@gmail.com

\begin{abstract}
Resumo
A biogeografia enquanto ciência permite compreender as espécies da fauna e da flora sobre áreas do espaço geográfico, além de possui uma importância para o aluno, pois através dela ele passa a compreender e se inserir como um ser constituinte do meio e que exerce influencia sobre o mesmo. Assim, em detrimento da crescente urbanização em Belém- Pa e a falta de conhecimento a cerca da importância que ela possui, o presente artigo busca relatar atividades biogeográficas aplicadas na sala de aula e em campo no Jardim Botânico Rodriguez Alves com o intuito de conscientizar os alunos a cerca da importância da preservação da fauna e flora da região amazônica e manutenção dos recursos naturais que ela possui. Para a realização das atividades foram realizados levantamentos bibliográficos sobre a temática, ida a campo e recursos didáticos- pedagógicos para aproximar o aluno do seu cotidiano. As atividades foram aplicadas através do PIBID mediante o subprojeto de "Um olhar Biogeográfico dos Parques Ambientais da Grande BelémPA" financiado pela CAPES e vinculado a Universidade da Amazônia.
\end{abstract}

Palavras-chave: Biogeografia. Atividades. Parques Ambientais.

\begin{abstract}
The biogeography as a science allows us to understand the species of fauna and flora on areas of geographical space, and has an importance for the student, because through it he comes to understand and enter as a constituent of the medium being and exercising influence on the same. Thus, at the expense of increasing urbanization in Belém-PA and the lack of knowledge about the importance that it has, this article seeks report biogeographical activities applied in the classroom and in the field in the Botanical Garden Rodriguez Alves in order to educate students about the importance of preserving the fauna and flora of the Amazon region and maintenance of natural resources that it has. To carry out the activities were carried out literature surveys on the subject, going to the field and pedagogical didáticosresources to bring the student of their daily lives. The activities were implemented through PIBID by the subproject "A Biogeographic look Environmental Parks Belém-PA" supported by CAPES and linked the University of Amazonia.
\end{abstract}

Keywords: Biogeography. Activities. Environmental Park

\section{INTRODUÇÃO}

A temática da biogeografia é pouco aplicada na sala de aula do ensino básico através de procedimentos metodológicos. Ela faz parte da ciência geográfica onde busca compreender a relação entre a natureza e sociedade. Atuando de forma a compreender a distribuição geográfica dos seres vivos no espaço, como conceitua (DANSEREAU, 1949) é “a ciência que estuda a distribuição, a adaptação, a expansão e associação das plantas e dos animais (ou seres vivos)”. O estudo dela para o geografo, segundo Camargo \& Troppmair:

\footnotetext{
${ }^{1}$ Ananda do Socorro Oeiras Paixão, Graduanda do Curso de Licenciatura em Geografia, Bolsista do subprojeto "um olhar biológico e geográfico dos parques ambientais da grande Belém/Pa” - PIBID, Universidade da Amazônia, Belém-PA,Brasil.

${ }^{2}$ Anderson Coelho Borges, Graduando do Curso de Licenciatura em Geografia, Bolsista do subprojeto "um olhar biológico e geográfico dos parques ambientais da grande Belém/Pa" - PIBID, Universidade da Amazônia, Belém-PA, Brasil.
} 
(...) um trabalho biogeográfico do ponto de vista do 'geógrafo', tem necessidade de explicar a distribuição dos seres vivos (fauna e flora) no espaço, e correlacioná-las sempre com os demais aspectos ambientais (fatores abióticos) e o próprio Homem (fatores culturais), apresentando, assim, uma visão muito mais ampla e complexa (CAMARGO \& TROPPMAIR, p. 135, 2002).

A Biogeografia representa na atualidade, um ponto chave para os debates atuais da sociedade moderna e sua relação com o meio ambiente. Desta maneira, iniciaremos nossos estudos biogeográficos através da análise dos conceitos que envolvem a disciplina, tentando contextualizar essas informações à prática pedagógica em sala de aula através do Programa Institucional de Bolsas de Iniciação à Docência PIBID, de forma que os estudos possam ser desenvolvidos de maneira prática e agradável, acreditando que desse modo, os alunos poderão compreender e sistematizar o conhecimento biogeográfico.

Assim, coube a nós acadêmicos de Licenciatura em Geografia, através do uso de métodos e técnicas específicas compreender os processos e leis naturais que determinam a dinâmica das paisagens, como também o uso racional do espaço e dos recursos naturais, tendo como objeto de estudo a biodiversidade amazônica presente no JBA, neste sentido, visamos mostrar a importância da biogeografia no processo de aprendizagem da geografia física. O presente trabalho é o desdobramento da pesquisa do subprojeto de Geografia e Biologia "Um olhar biogeográfico dos Parques Ambientais da Grande Belém", desenvolvido no âmbito do Programa Institucional de Bolsa de Iniciação á Docência - PIBID/UNAMA realizada junto á Escola Estadual de Ensino Fundamental e Médio Santana Marques.

Buscamos relatar as atividades biogeográficas adotadas em sala de aula e em idas ao campo através do PIBID consistindo em uma abordagem biológica e geográfica, tendo em vista que o subprojeto é interdisciplinar com o intuito de conscientizar os alunos a cerca da importância da preservação da fauna e flora da região amazônica assim como a manutenção dos recursos naturais que ela possui, utilizando desses recursos didáticos metodológicos que auxiliem no processo de ensino-aprendizagem como, por exemplo: projetos de pesquisa e extensão, dramatização, produtos cartográficos, música, feiras, trabalho em grupo e o debate, que são considerados estratégicos no ensino e como formas de avaliação, que tem a finalidade de promover a aprendizagem (SELBACH, 2010).

Concomitantemente, a Secretaria de Educação Fundamental introduz:

Assim a Biogeografia para o geógrafo deve ser entendida e aplicada. Por ela ser pouco abordada no ensino básico, requer uma busca de métodos a serem abordados nas escolas, pautadas pelo PCN's que propõe um trabalho pedagógico que visa à ampliação das capacidades dos alunos do ensino fundamental de observar, conhecer, explicar, comparar e representar as características do lugar em que vivem e de diferentes paisagens e espaços geográficos (PCN's, 1998, p15). 
Desta maneira, iniciaremos nossos estudos biogeográficos através da análise dos conceitos que envolvem a disciplina, tentando contextualizar essas informações à prática pedagógica em sala de aula, de forma que os estudos possam ser desenvolvidos de maneira prática e agradável, acreditando que desse modo, os alunos poderão compreender e sistematizar o conhecimento biogeográfico, no que se refere a fauna e sua distribuição geográfica no campo de estudo expondo na primeira atividade imagens disponíveis do Jardim Botânico.

\section{METODOLOGIA}

Foram feitas duas aulas que antecederam à visita a aula prática, para o reconhecimento biogeográfico "in loco". Além de anotações, registros fotográficos referentes ao nosso campo de estudo, exemplificando as espécies disponíveis no Bosque. Após isso foi montado um questionário de aula expositiva acerca dos assuntos mencionados na visita, também foram ministradas aulas expositivas relacionando a teoria biogeográfica de Troppmair com a prática, dessa forma fazendo um paralelo com a disciplina.

Os estudos e as atividades realizadas tiveram como foco central o Jardim Botânico da Amazônia - JBA conhecido como Bosque Rodrigues Alves que está localizado no bairro do Marco (figura 01), às margens da Avenida Almirante Barroso, umas das principais vias urbanas de circulação da cidade de Belém. O bosque foi escolhido por ser de fácil acesso pelos alunos, além de possui mais de $80 \%$ de espécies vegetais e por abrigar 435 animais de 29 espécies que vivem em cativeiro e também 29 em liberdade ou semiliberdade que estão dispersas na área de mata.

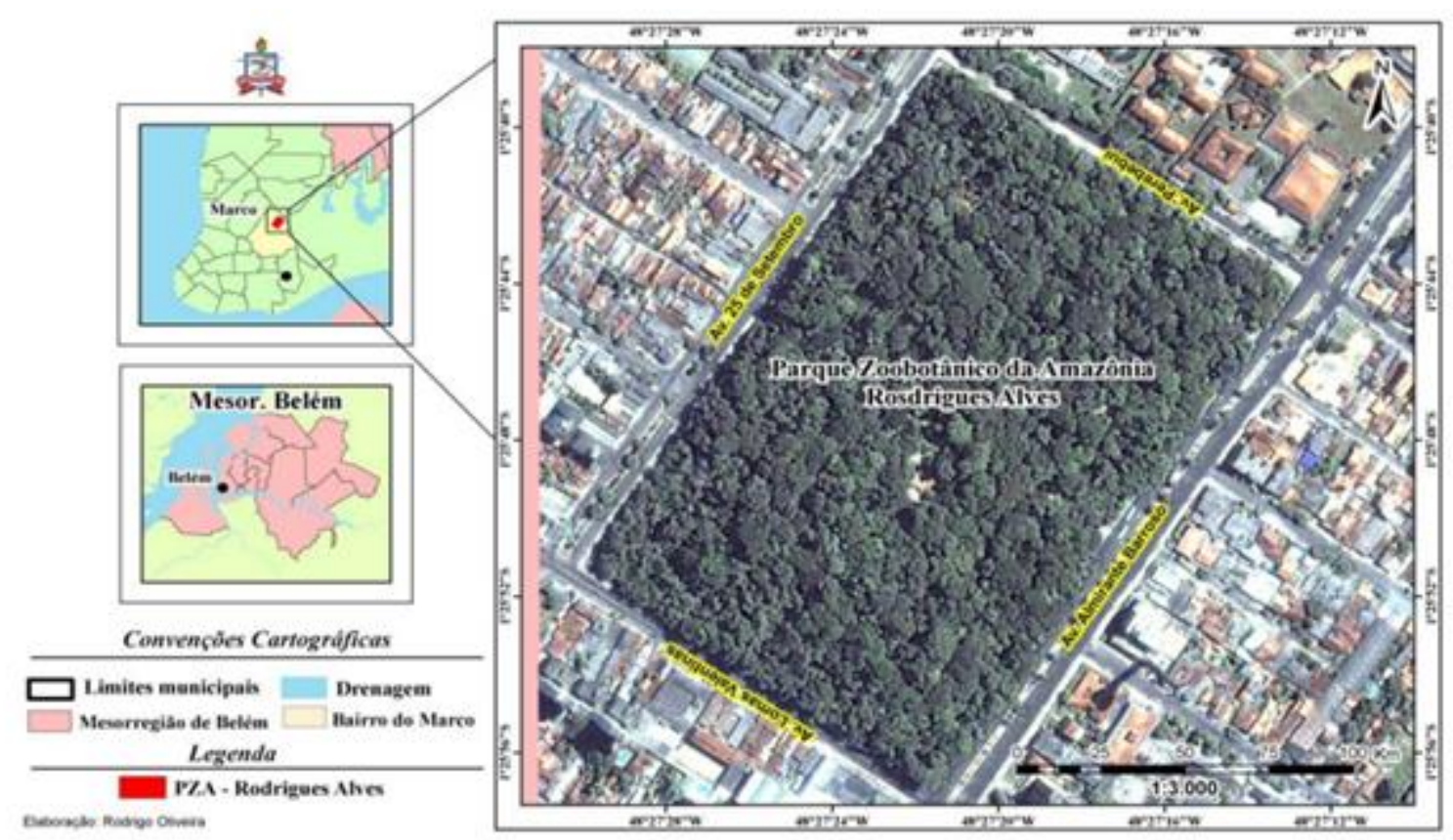

Figura 01. Mapa de localização do Jardim Botânico da Amazônia. Fonte: (DA LUZ, p.174, 2002). 
As atividades foram realizadas com os alunos do $7^{\circ}$ ano do ensino Fundamental da Escola Estadual de Ensino Fundamental e Média Santana Marques, Localizado no Bairro do Panorama na cidade de Belém do Pará. Para a realização das atividades foi realizado primeiramente o levantamento bibliográfico em artigos, livros e meios eletrônicos disponíveis sobre biogeografia e ensino de geografia, além de idas a campo com os alunos e recursos didático-pedagógicos para aproximar o aluno da realidade.

\section{RESULTADOS E DISCUSSÃO}

\subsection{ATIVIDADES EM SALA DE AULA: A BIOGEOGRAFIA (ORIGENS DOS ANIMAIS VERTEBRADOS DO BOSQUE RODRIGUES ALVES EM BELÉM-PA)}

A matéria, em geral, não costuma exigir os pré-requisitos que seriam necessários para uma “compreensão total” desta área do saber. Em vez disso, são exigidos pré-requisitos de uma típica "formação básica" em Geografia, Ecologia, Zoologia e Botânica, desta forma, deveriam ser apresentadas como disciplinas do currículo mínimo em Geografia, a fim de favorecer um mais eficiente aproveitamento na disciplina. Ademais, os conceitos básicos, deveriam ser mais bem destrinchados por outras disciplinas, anteriores à Biogeografia, no intuito de propiciar de fato uma compreensão da área de conhecimento.

Para que se compreenda a biogeografia é necessário entender a importância da distribuição geográfica dos seres vivos na terra. Assim o Bosque Rodrigues Alves veio a contribuir com a atividade, tendo em vista que ele abriga uma diversidade de espécies de animais de origem amazônica, ajudando, portanto na manutenção da fauna no planeta.

A atividade consistiu em análise bibliográfica feita pelos alunos, através de consultas ao site do Bosque que possui uma página na Internet que disponibiliza informações a cerca da história, da fauna e flora do espaço público localizado na área urbana da cidade de Belém.

Primeiramente o professor/supervisor de Geografia de acordo com seu conteúdo programático do ano, ministrou uma aula sobre a distribuição geográfica dos seres vivos no planeta e o professor/ supervisor de Biologia deu uma aula sobre os animais vertebrados da região amazônica. Após esse momento os Bolsistas do PIBID mediante o subprojeto elaboraram uma atividade onde os alunos foram divididos em grupos e para cada um foi dado um tipo de espécie (Aves, Mamíferos, Répteis e Anfíbios). Com o auxilio dos supervisores de Geografia e Biologia, os alunos do $7^{\circ}$ ano do ensino fundamental fizeram uma pesquisa bibliográfica a cerca das espécies de animais que existem no Bosque Rodrigues Alves.

Além da pesquisa, os alunos preencheram uma ficha na qual continha o: nome popular da espécie, nome cientifico, família, ordem, classe, origem geográfica, ambiente e curiosidades que 
encontraram. A partir desse momento os grupos construíram um mapa da região amazônica, onde deveria está contida a através de símbolos criados no mapa pelos alunos as espécies encontradas no Bosque e que tinham a origem geográfica nessa região (Figura 02). Mediante a isso, os alunos expuseram a pesquisa realizada, falando detalhadamente de cada animal pesquisado e mostrando no mapa criado por eles onde se dava a origem geográfica de cada uma das espécies, além de falarem sobre as espécies ameaçadas de extinção e quem são seus principais predadores e as consequências que isso acaba ocasionando para o planeta.

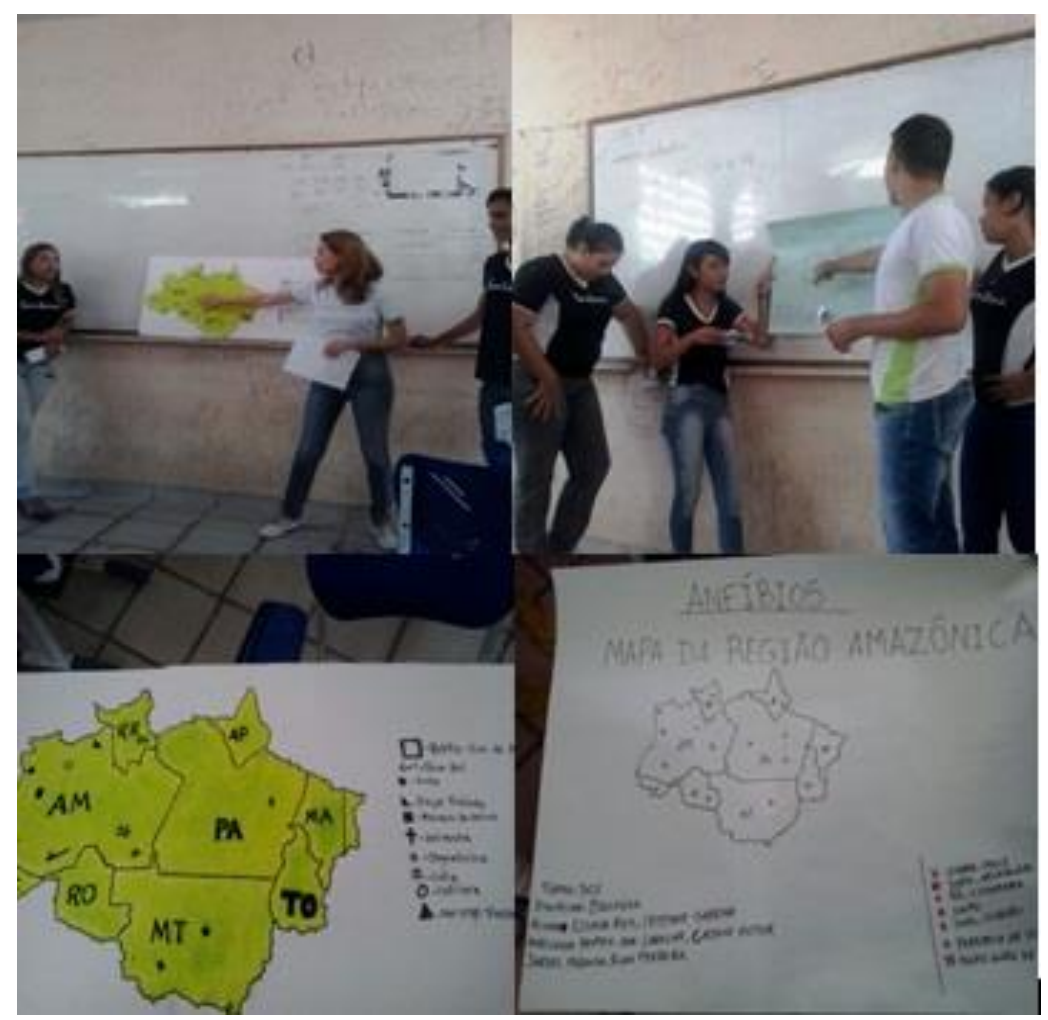

Figura 02. Apresentação da atividade realizada sobre o Bosque Rodrigues Alves Fonte: Pesquisa de Campo, 2016.

O seminário foi apresentado mostrando no mapa as características de cada espécie que havia no Bosque, levantando debates na turma em relação à origem geográfica de cada uma das espécies como: mamíferos, aves, répteis e anfíbios e principalmente as curiosidades de cada um deles, levando-os a enfatizar na preservação, tendo em vista que os alunos reconheceram o nível de importância deles para o próprio homem. Atentando, portanto para uma conscientização ambiental.

A Biogeografia é importante para se compreender a forma como as espécies estão distribuídas pelas diferentes regiões, unidades espaciais e ambientes. As informações levantadas durante a pesquisa pode auxiliar no desenvolvimento de teorias, na mudança das formas de abordagem e no conhecimento das paisagens.

\subsection{VISITA DE CAMPO AO BOSQUE ROBRIGUES ALVES EM BELÉM-PA.}


Em um segundo momento após a atividade realizada em sala de aula, os alunos foram levados ao Bosque Rodrigues Alves para compreenderem melhor a fauna, a flora e principalmente o histórico desse monumento, assim como sua importância no meio urbano para a cidade e população de Belém. A visita a campo foi realizada tendo o acompanhamento dos bolsistas do subprojeto de biologia e geografia, assim como os supervisores e com a ajuda de funcionários do bosque, sendo um historiador, uma engenheira ambiental e uma zootecnista.

Os alunos entraram pelo lado esquerdo do bosque onde foram recebidos pelo historiador que relatou um pouco sobre a criação do lugar pelo então presidente da câmara municipal de Belém João Diogo Clemente Malcher em 1883, ressaltando a ideia que o espaço foi construído em virtude da necessidade de se ter espaços de lazer para a população, tendo em vista que Belém passava por um momento financeiro muito proveito através da exploração do Látex. (HISTÓRICO DO BOSQUE, 2005). Outro fator principal para a implantação de áreas de lazer era que Belém se inspirava no modelo da cidade de Paris com áreas arborizadas e ajardinadas.

Assim o historiador foi descrevendo as reformas pelo qual o espaço passou e a importância de sua permanência até os dias de hoje no lado urbano da cidade de Belém. Onde o Bosque garante tranquilidade e conforto em meio à correria que as grandes cidades possuem. Existem outras funções desses espaços verdes como citado abaixo:

\begin{abstract}
As áreas verdes urbanas cumprem funções importantes nas cidades como: 1.Função climática de controle da radiação solar, diminuição da temperatura, aumento da umidade do ar e redução da poluição do ar. Em cidades de clima quente como Belém, o sombreamento desempenha um papel importante na amenização da radiação solar e melhoria no conforto térmico; 2. Função ecológica através da conservação de espécies nativas e exóticas nas áreas urbanas; 3 . Função social relacionada a possibilidade de lazer e sociabilidade de áreas verdes com adequada infraestrutura para o desenvolvimento de atividades físicas; 4.Função sócio-educativa uma vez que são espaços importantes para a realização de atividades de educação ambiental que promovam a conscientização da preservação do patrimônio ambiental e ecossistemas brasileiros e; 5. Função estética que torna possível a diversificação e embelezamento da paisagem urbana nas cidades (DA LUZ, p.175, 2012).
\end{abstract}

Depois desse momento da relevância do espaço e histórico do bosque, os alunos foram conhecer com ajuda da engenheira ambiental a flora que existe na área, como as medicinais e árvores ameaçadas em extinção. Onde ela relatou sobre as arvores centenárias que o bosque possui como a Quariquara que permanece no espaço a cerca de aproximadamente 400 anos, assim como a Maçaranduba que tem 150 anos no local e a seringueira, espécie de fundamental importância para a economia da região amazônica no período de 1879 a 1912. Além de relatar um pouco sobre as características da folha delas levando em consideração a região nativa que é a amazônica, a altura que elas possuem chegando de 60 há 65 metros. Os alunos ainda puderam conhecer as espécies típicas da região que servem de consumo para os mesmos como a castanheira (Bertholetia excelsa), bacurizeiro (Platonia insignis) e o cupuaçu (Theodroma grandiflorum). Depois foi explicada a 
importância dessa flora para os alunos, descrevendo o clima como fator de beneficio que ela trás para a região urbana da cidade, ressaltando, portanto, a importância do homem não desmatar esse bem natural.

Por fim, os alunos tiveram uma aula sobre a fauna no Bosque tendo o auxilio de uma zootecnista e o supervisor de Geografia, onde os alunos aprenderam sobre as características dos animais do local, assim como sua distribuição e organização geográfica na região amazônica, bem como as peculiaridades e as ações antrópicas que acabam afetando as espécies e suas consequências para o meio ambiente. A atividade contou com a exploração dos animais que estão em difíceis visualizações pelos alunos no seu cotidiano, portanto, os ameaçados em extinção.

\subsection{ANÁLISES DA FAUNA}

O Bosque Rodrigues Alves possuem animais que viveram em cativeiros e foram levados para lá em condição de liberdade e semiliberdade, uns em condições de reabilitação, pois eles foram encontrados em condições de extremos maus tratos pelo homem. Além de possuírem animais ameaçados de extinção como a Arara azul grande, que foi muito assediada pelos alunos na visita. $\mathrm{O}$ peixe boi da Amazônia também participou do processo de aprendizagem dos alunos em detrimento de ser a espécie de animal mais conhecida da região amazônica através das lendas e por atualmente está classificado em ameaça de extinção pela fácil vulnerabilidade em que ele se encontra na natureza.

As fotos a seguir mostram a vivencia dos alunos em uma atividade de campo no Bosque, aonde veio contribuir com o conhecimento deles através de atividades realizadas em sala de aula.

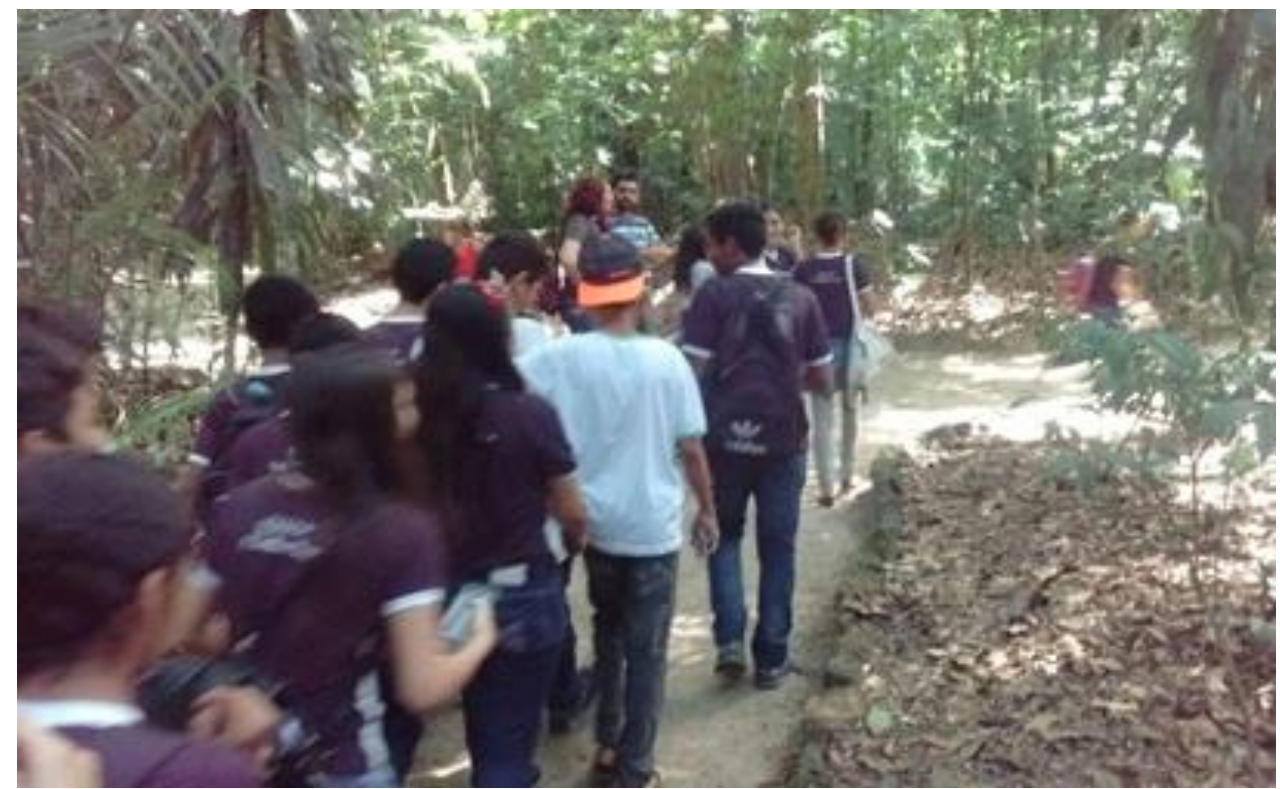

Figura 03. Análise da Fauna do Bosque. Fonte: Ananda do Socorro Oeiras Paixão, trabalho de Campo, 2016. 


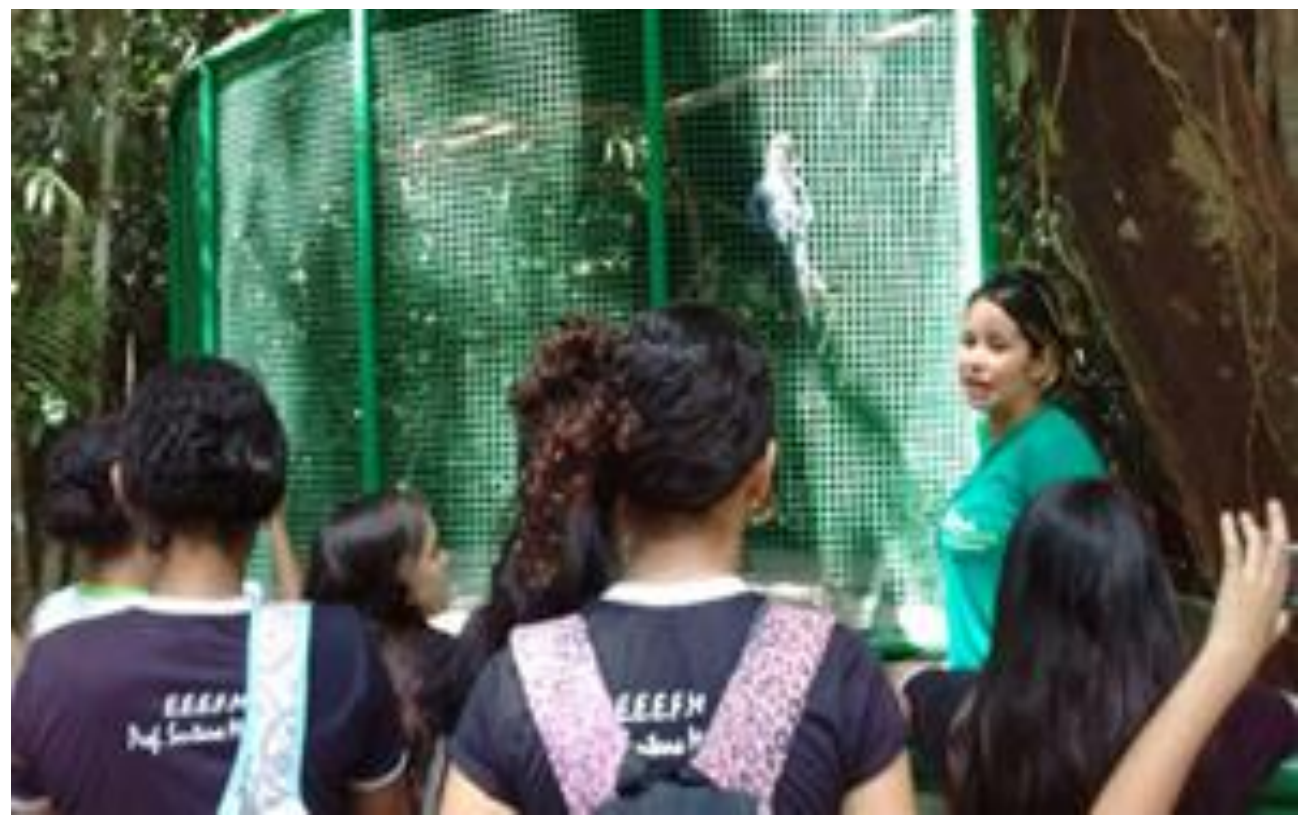

Figura 04. exposição sobre os animais ameaçados de extinção. Fonte: Ananda do Socorro Oeiras Paixão, trabalho de Campo, 2016.

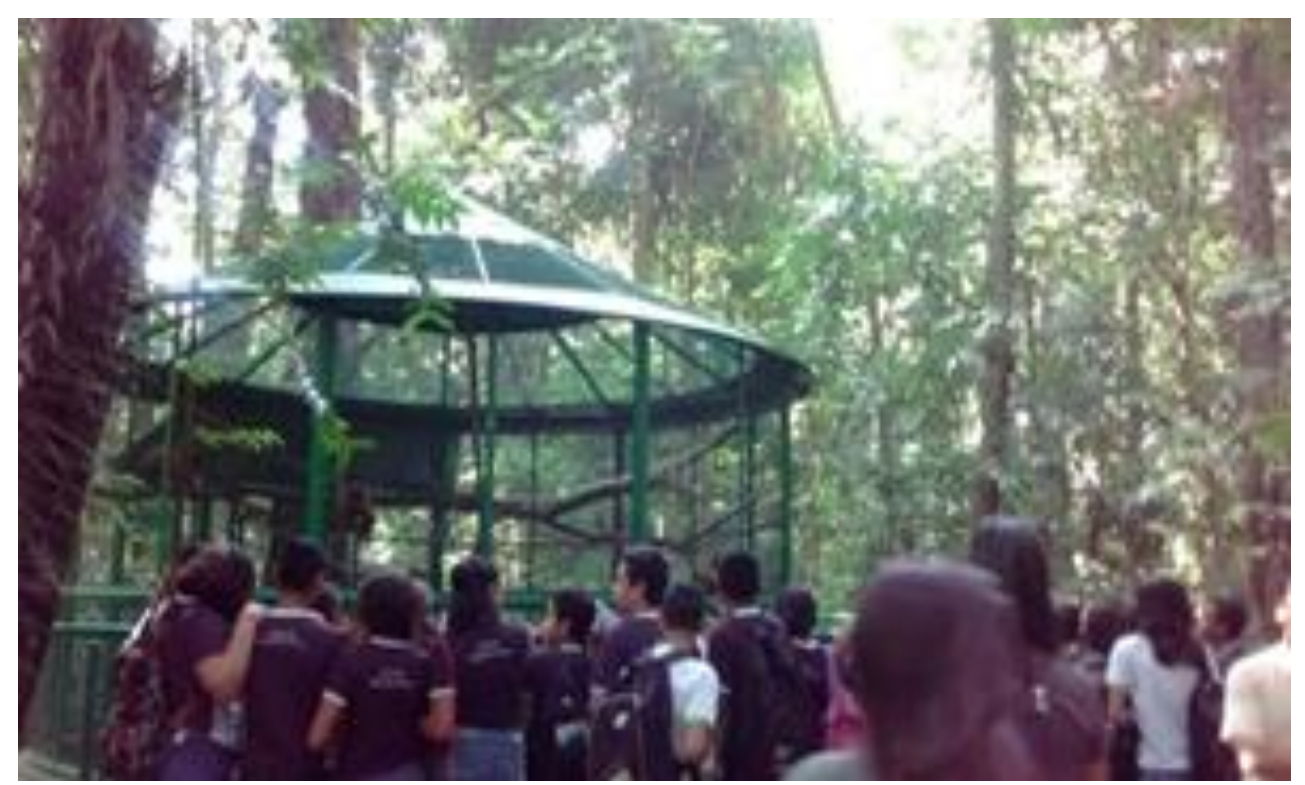

Figura 05. Observação da Fauna do Bosque Rodrigues Alves. Fonte: Ananda do Socorro Oeiras Paixão, trabalho de Campo, 2016.

Através da atividade em Campo os alunos puderam compreender melhor a Fauna e a Flora nativa da região amazônica e que estão localizadas no Bosque Rodrigues Alves, assim como sua importância para o homem, sensibilizando os, portanto, quanto a importância de cuidar do meio ambiente e o papel que eles desempenham para que não haja consequências ambientais na terra.

\subsection{ANÁLISES DA FLORA}

Quanto à Folhagem: A vegetação é latifoliada, caracteriza-se por apresentar folhas grandes e largas, predominantes no ambiente de clima quente chuvoso, possuem maior facilidade para funções fotossintéticas e de transpiração. 
Quanto à Umidade: Vegetação higrófila, aparece em regiões em muita umidade, como é o caso da nossa região amazônica, a exemplo da bananeira.

Quanto ao Porte: apresenta grande tamanho, como é o exemplo da floreta.

Quanto ao Aspecto: Vegetação fechada mantém-se com vegetais muito próximos um dos outros apresentando uma feição densa.

Quanto à Variedade dos Vegetais: Vegetação heteróclita ou heterogênea, é rica em espécies de vegetais, a exemplo das floretas equatoriais e tropicais. (Figura6).

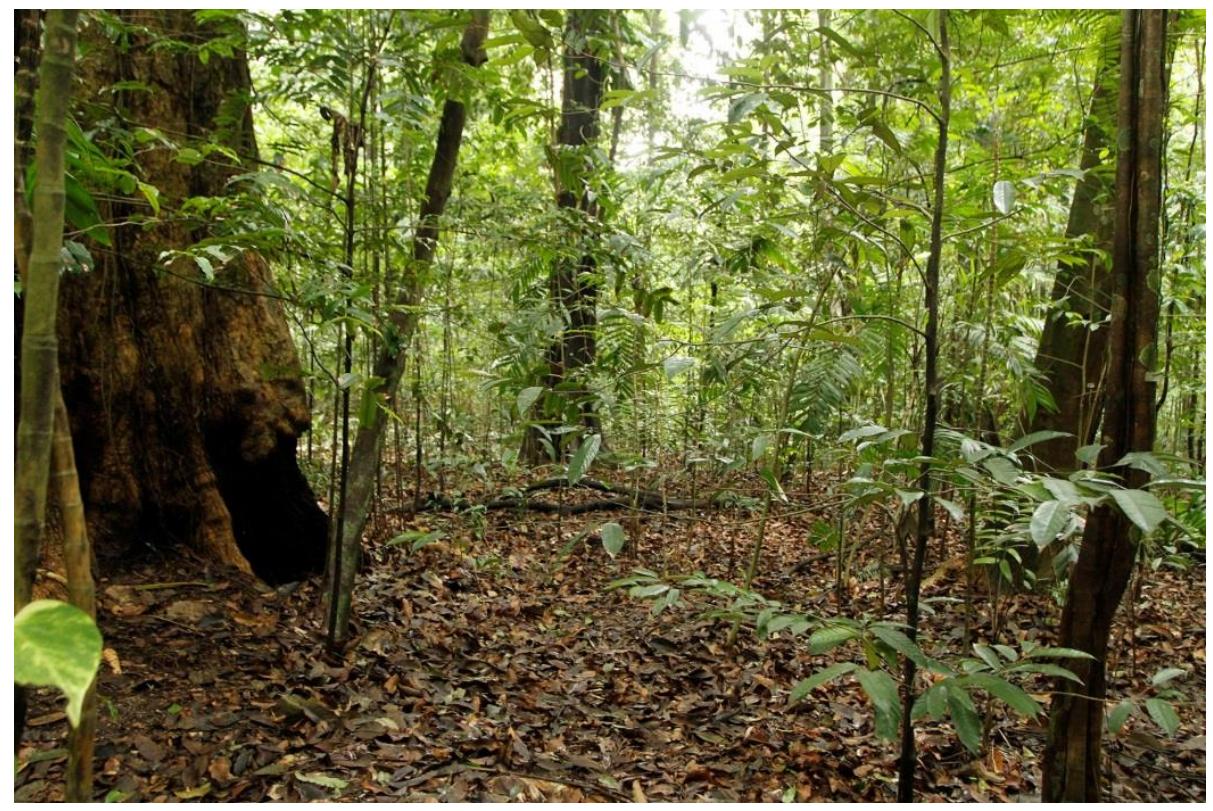

Figura 06: Identificação da flora amazônica do Bosque Rodrigues Alves. Fonte: Oswaldo, Secretaria Municipal de Meio Ambiente (SEMMA)

A biogeografia, portanto, proporcionou através dessa atividade um olhar amplo do aluno, passando a desenvolver uma visão de preservar o meio ao qual está inserido, bem como em fomentar com outras pessoas a importância da não agressão a natureza, desenvolvendo neles uma educação ambiental. Além do papel importante que o Bosque desempenha no centro urbano da cidade de Belém do Pará.

\section{CONSIDERAÇÕES FINAIS}

A Biogeografia proporcionou para os alunos uma visão primeiramente teórica através de atividades realizadas em sala de aula e posteriormente a prática com visita a campo, levando-os a complementar seu entendimento a cerca das características da fauna e da flora que o bosque detém. Além de compreenderem a importância que o Bosque Rodrigues Alves desempenha da cidade de Belém, sendo um dos poucos espaços arborizados que a cidade possui.

Os alunos ainda puderam compreender os aspectos climáticos de diferentes pontos da área urbana da cidade, onde a ausência e presença de vegetação arbórea acabam por influenciar no clima 
da área. Mediante isso, foi possível um olhar minucioso a cerca da paisagem da cidade, tendo como foco a vegetação.

Diante das atividades realizadas tendo o Bosque Rodrigues Alves como área de estudo, foi possível compreender em sua plenitude o espaço geográfico através da Biogeografia, desde o conhecimento da distribuição e origem de cada espécie, além da intervenção do homem na natureza, fomentando os impactos que isso acaba gerando nela. Atentando para uma sensibilização e conscientização ambiental por parte do aluno, pois a Biogeografia proporciona através do seu estuda uma visão a cerca da importância de cuidar do meio ambiente.

\section{REFERÊNCIAS}

BOSQUE RODRIGUES ALVES JARDIM BOTÂNICO DA AMAZÔNIA. Histórico do Bosque Rodrigues Alves. Adaptação de Biblioteca Bosque Rodrigues Alves. Belém, 2005.

CAMARGO, J. C. G.; TROPPMAIR, H. A evolução da biogeografia no âmbito da ciência geográfica no Brasil. Geografia, v. 27, n. 3, p. 133-156, 2002.

DA LUZ, L. M.; ARRA, R. R. M.; DE OLIVEIRA, S. R. EDUCAÇÃO AMBIENTAL EM ÁREAS VERDES URBANAS COMO RECURSO DIDÁTICO PARA O ENSINO DE BIOGEOGRAFIA. REVISTA GEONORTE, v. 3, n. 6, p. 171-177, 2016.

DANSEREAU, P. “Os planos da Biogeografia”. Revista Brasileira de Geografia, ano VIII, n.2, abril-junho, 1946.

NACIONAIS, Parâmetros Curriculares. Secretaria de Educação Fundamental. Brasília: MEC/SEF, v. 1998, p. 156.

SELBACH, S. História e didática. Petrópolis, RJ: Vozes, 2010. Disponível em: <http://www.ipea.gov.br/desafios/index.php?option=com_content\&id=2154: catid=28\&Itemid=23>. Acesso em: 20 Ago 2015.

Recebido em: 14/08/2016

Aceito para publicação em: 01/10/2016 